\title{
Long-term effects on haemostatic variables of three ad libitum diets differing in type and amount of fat and carbohydrate: a 6-month randomised study in obese individuals
}

\author{
Else-Marie Bladbjerg ${ }^{1}{ }^{*}$, Thomas M. Larsen ${ }^{2}$, Anette Due ${ }^{2}$, Jørgen Jespersen ${ }^{1}$, Steen Stender $^{3}$ \\ and Arne Astrup ${ }^{2,4}$ \\ ${ }^{1}$ Unit for Thrombosis Research, Institute of Public Health, The University of Southern Denmark and Department of Clinical \\ Biochemistry, Hospital of South West Denmark, Esbjerg, Denmark \\ ${ }^{2}$ Department of Human Nutrition, Faculty of Life Sciences, Centre for Advanced Food Studies, University of Copenhagen, \\ Frederiksberg, Denmark \\ ${ }^{3}$ Department of Clinical Chemistry, Copenhagen University Hospital, Gentofte, Denmark \\ ${ }^{4}$ Department of Clinical Nutrition, Copenhagen University Hospital, Gentofte, Denmark
}

(Received 17 February 2010 - Revised 3 May 2010 - Accepted 7 May 2010 - First published online 30 July 2010)

Diet is important in the prevention of CVD, and it has been suggested that a diet high in MUFA is more cardioprotective than a low-fat diet. We hypothesised that the thrombotic risk profile is improved most favourably by a high-MUFA diet compared with a low-fat diet. This was tested in a parallel randomised intervention trial on overweight individuals (aged 28.2 (SD 4.6) years) randomly assigned to a diet providing a moderate amount of fat (35-45\% of energy; $>20 \%$ of fat as MUFA) (MUFA diet; $n$ 39), to a low-fat (LF; 20-30\% of energy) diet ( $n$ 43), or to a control diet (35\% of energy as fat; $n$ 24) for 6 months after a weight loss of about $10 \%$. Protein constituted $10-20 \%$ of energy in all three diets. All foods were provided free of charge from a purpose-built supermarket. Fasting blood samples were collected before and after intervention and analysed for factor VII coagulant activity (FVII:c), fibrinogen, prothrombin fragment $1+2$ (F1 +2 ), D-dimer and plasminogen activator inhibitor (PAI). The fibrinogen concentration was significantly lowered by the LF diet, but not by the MUFA diet. Changes in fibrinogen differed significantly between diet groups. BMI and PAI concentration increased and D-dimer concentrations were reduced irrespective of the diets. No changes were observed for FVII:c and F1 +2 . Our findings suggest that in overweight subjects after weight loss the thrombotic risk profile is improved most favourably by the LF diet compared with the MUFA diet based on the reduction in fibrinogen concentrations.

Diet intervention: Long-term studies: MUFA: Randomised studies: Thrombotic risk

Diet is an important factor in the prevention of CVD as demonstrated in The Nurses' Health Study, a large prospective study in 121700 initially healthy nurses ${ }^{(1)}$, in which high intakes of SFA, trans-fatty acids and carbohydrates with a high glycaemic index (GI) were associated with increased CVD risk $^{(1,2)}$, and high intakes of MUFA and PUFA were associated with reduced CVD risk ${ }^{(1)}$.

Recently, an alternative dietary pyramid was introduced in the USA by one of the Nurses' Health Study investigators ${ }^{(3)}$. The main difference between Willett's new pyramid and the US Department of Agriculture (USDA) 2004 Food Pyramid is that the new pyramid has no restrictions on fat as long as it is of vegetable origin, and the carbohydrates should have a high content of whole grains. Such a diet is assumed to have a more cardioprotective effect than a diet following the USDA 2004 Food Pyramid. Although the Nurses' Health Study is a very large and well-designed study, the study conclusions should not alone be used to change the established dietary recommendations without also having results from long-term controlled comparisons with existing dietary recommendations. Because a controlled randomised dietary study in healthy individuals with CVD as the end point will be practically infeasible, CVD risk markers can be studied as an alternative.

Thrombosis is a key factor in CVD as illustrated by the association between plasma concentrations of haemostatic variables and the risk of CVD in prospective studies. Associations have been observed for fibrinogen ${ }^{(4)}$, the fibrin degradation product D-dimer ${ }^{(5)}$, plasminogen activator inhibitor (PAI)- $1^{(6,7)}$, and factor VII coagulant activity (FVII:c) ${ }^{(8)}$. A large number of studies have reported an effect of specific dietary components on these CVD risk markers, for example, effects of dietary fat on factor VII (FVII) ${ }^{(9-11)}$, but only a few studies have looked at the long-term effects of complex dietary changes ${ }^{(12-14)}$.

Abbreviations: F1 + 2, prothrombin fragment $1+2$; FVII, factor VII; FVII:c, factor VII coagulant activity; GI, glycaemic index; LF, low-fat; PAI, plasminogen activator inhibitor.

* Corresponding author: Dr Else-Marie Bladbjerg, fax +45 79182430, email ebladbjerg@health.sdu.dk 
The aim of the present study was to compare the long-term effect on haemostatic variables of three different ad libitum diets in a 6-month strictly controlled dietary intervention in healthy obese subjects after weight loss. The diets compared were Willett's new Healthy Eating Pyramid (high in MUFA and low in GI), the Official Nordic Dietary Guidelines (low in fat and medium in GI) and the average Danish diet (high in SFA and high in GI). We hypothesised that the thrombotic risk profile will be improved most favourably by the diet high in MUFA and low in GI.

\section{Experimental methods}

\section{Study population}

The dietary intervention, Mono Unsaturated Fatty acids in Obesity (MUFObes), was conducted at the Department of Human Nutrition, Faculty of Life Sciences, University of Copenhagen (Frederiksberg, Denmark) and has been described in detail elsewhere ${ }^{(15,16)}$. Briefly, 131 obese individuals were randomly assigned to one of three diets. The inclusion criteria were aged $18-35$ years, BMI $28-36 \mathrm{~kg} / \mathrm{m}^{2}$, body weight fluctuations of $<3 \mathrm{~kg}$ over the previous 2 months, and a nonsmoking status. Subjects were healthy and took no regular medicine other than contraceptive pills. All subjects gave oral and written informed consent, and the Ethics Committee of the Municipalities of Copenhagen and Frederiksberg approved the study according to the Helsinki Declaration. The trial was registered at clinicaltrials.gov as NCT00274729.

The population characteristics at study entry are described in Table 1. For various reasons, twenty-five participants dropped out during the intervention period leaving thirtynine participants in the MUFA group, forty-three participants in the low-fat (LF) group, and twenty-four participants in the control group ${ }^{(15)}$.

\section{Study design}

The study was a parallel intervention trial comparing the effect of three diets on body weight and cardiovascular risk after 6 months of intervention. The study design is presented in Fig. 1 and has been described in detail previously ${ }^{(15)}$. After an initial 8-week low-energy diet, only subjects who lost $>8 \%$ of their body weight were randomised to one of

Table 1. Population characteristics at study entry*

(Mean values and standard deviations)

\begin{tabular}{|c|c|c|c|c|c|c|}
\hline \multirow[b]{2}{*}{ Variable } & \multicolumn{2}{|c|}{$\begin{array}{l}\text { High-MUFA } \\
\text { diet }(n 54)\end{array}$} & \multicolumn{2}{|c|}{$\begin{array}{l}\text { Low-fat diet } \\
\quad(n 51)\end{array}$} & \multicolumn{2}{|c|}{$\begin{array}{l}\text { Control diet } \\
\quad(n 26)\end{array}$} \\
\hline & Mean & SD & Mean & SD & Mean & SD \\
\hline Age (years) & $29 \cdot 2$ & 4.5 & $27 \cdot 3$ & 4.9 & $27 \cdot 6$ & $5 \cdot 1$ \\
\hline \multicolumn{7}{|l|}{$\operatorname{Sex}(n)$} \\
\hline Male & \multicolumn{2}{|c|}{22} & \multicolumn{2}{|c|}{22} & \multicolumn{2}{|c|}{11} \\
\hline Female & \multicolumn{2}{|c|}{32} & \multicolumn{2}{|c|}{29} & \multicolumn{2}{|c|}{15} \\
\hline Body weight (kg) & 95.4 & $12 \cdot 8$ & $96 \cdot 9$ & 13.5 & 93.9 & $13 \cdot 8$ \\
\hline Height (m) & 1.74 & 0.1 & 1.75 & 0.1 & 1.73 & 0.1 \\
\hline $\mathrm{BMI}\left(\mathrm{kg} / \mathrm{m}^{2}\right)$ & 31.4 & $2 \cdot 7$ & 31.6 & $2 \cdot 7$ & 31.3 & 2.5 \\
\hline
\end{tabular}

${ }^{*}$ Measurements were made at screening before weight loss. Mean values for the three diets were compared with an ANOVA. Sex was compared with the $\chi^{2}$ test. No significant differences existed between the groups at study entry.

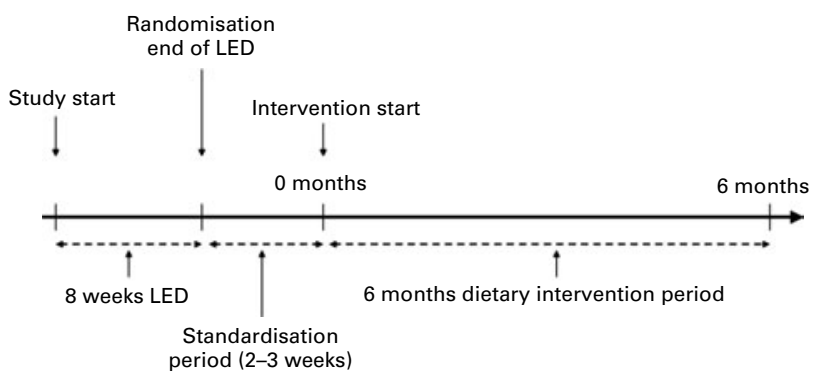

Fig. 1. Design of the Mono Unsaturated Fatty acids in Obesity (MUFObes) study. LED, low-energy diet.

the experimental diets. After randomisation, the participants completed a 3-week standardisation period (weight stabilisation and adaptation to the supermarket model) eating a diet resembling the average Danish diet, corresponding to the control diet. The 6-month intervention study started in May 2004 and ended in November 2004.

\section{Experimental diets}

The 6-month dietary intervention was based on an ad libitum design in order to mimic free-living conditions and to test the real appetite regulation of the diets. There were three prescribed diets. (1) The MUFA diet was designed to be moderate in fat $(35-45 \%$ of energy), high in MUFA $(>20 \%$ of energy) and moderate in low-GI carbohydrates (40-50\% of energy) with a high content of vegetable oils, whole-grain food, nuts and legumes. (2) The LF diet was low in fat (20-30\% of energy) and high in mixed-GI carbohydrates (55-65\% of energy). (3) The control diet corresponded to the average Danish diet and was moderate in fat (30-40\% of energy), high in SFA ( $>15 \%$ of energy), moderate in high-GI carbohydrates (45-55\% of energy) and low in fibre $(<3 \%$ of energy). All three diets were moderate in protein (10-20\% of energy). Foods recommended for the three dietary groups have previously been described ${ }^{(15)}$. The actual dietary composition (Table 2) was in accordance with the prescribed dietary composition, and the biopsy content of fatty acids (assessment of compliance) was in accordance with the prescribed diets ${ }^{(15)}$.

\section{Supermarket foods, the computer program and shopping sessions}

To provide the subjects with all necessary foods and to accomplish a total recording of the food consumed, a validated supermarket model ${ }^{(17)}$ was established at the department. The supermarket foods, the computer program and the shopping sessions have been described extensively elsewhere ${ }^{(15,16,18)}$. Throughout the 6-month intervention, the subjects obtained all foods and beverages at the study supermarket, free of charge, and they were instructed to consume only these foods.

\section{Blood sampling}

Venous blood samples were drawn after lying in a supine position for $10 \mathrm{~min}$ after at least $10 \mathrm{~h}$ fasting, and $24 \mathrm{~h}$ abstention from alcohol and strenuous physical activity. 
Table 2. Actual nutrient composition of the experimental diets

(Mean values and $95 \%$ confidence intervals)

\begin{tabular}{|c|c|c|c|c|c|c|c|}
\hline & \multicolumn{2}{|c|}{ High-MUFA diet ( $n$ 39) } & \multicolumn{2}{|c|}{ LF diet ( $n$ 43) } & \multicolumn{2}{|c|}{ Control diet $(n 24)$} & \multirow[b]{2}{*}{$P \ddagger$} \\
\hline & Mean & $95 \% \mathrm{Cl}$ & Mean & $95 \% \mathrm{Cl}$ & Mean & $95 \% \mathrm{Cl}$ & \\
\hline Energy intake $(\mathrm{MJ} / \mathrm{d})$ & 11.5 & $10 \cdot 6,12 \cdot 4$ & 10.5 & $9 \cdot 7,11 \cdot 3$ & $10 \cdot 9$ & $9 \cdot 6,12 \cdot 3$ & 0.27 \\
\hline Total fat $(\mathrm{E} \%)$ & $38 \cdot 4^{\star \star \star}+† \dagger$ & $37 \cdot 9,39 \cdot 0$ & $23 \cdot 6^{\star * *}$ & $23 \cdot 1,24 \cdot 1$ & $32 \cdot 1$ & $31 \cdot 4,32 \cdot 7$ & $<0.001$ \\
\hline SFA (E\%) & $7 \cdot 1^{\star \star \star}+† \dagger$ & $6 \cdot 9,7 \cdot 4$ & $7 \cdot 9^{\star \star \star}$ & $7 \cdot 6,8 \cdot 3$ & $15 \cdot 1$ & $14 \cdot 7,15 \cdot 5$ & $<0.001$ \\
\hline MUFA (E\%) & $20 \cdot 2^{\star \star \star}+\dagger \dagger$ & $19 \cdot 8,20 \cdot 6$ & $8 \cdot 4^{\star \star \star}$ & $8 \cdot 1,8 \cdot 6$ & $10 \cdot 4$ & $10 \cdot 0,10 \cdot 8$ & $<0.001$ \\
\hline PUFA (E\%) & $7 \cdot 8^{\star \star \star} \dagger † \dagger$ & $7 \cdot 6,8 \cdot 1$ & $5 \cdot 2^{\star \star *}$ & $5 \cdot 1,5 \cdot 4$ & 4.0 & $3 \cdot 7,4 \cdot 3$ & $<0.001$ \\
\hline Carbohydrates (E\%) & $43 \cdot 3^{\star \star \star}+\dagger \dagger$ & $42 \cdot 7,43 \cdot 9$ & $57 \cdot 6^{\star \star *}$ & $57 \cdot 0,58 \cdot 2$ & $49 \cdot 8$ & $49 \cdot 2,50 \cdot 5$ & $<0.001$ \\
\hline Fibre (E\%) & $3 \cdot 8^{\star \star \star} \dagger † \dagger$ & $3 \cdot 7,4 \cdot 0$ & $3 \cdot 7^{\star \star \star}$ & $3.5,3.9$ & $2 \cdot 7$ & $2 \cdot 4,2 \cdot 9$ & $<0.001$ \\
\hline Added sugar (E\%) & $5 \cdot 4^{\star \star \star}+\dagger \dagger$ & $4.8,5.9$ & $7 \cdot 2^{\star \star \star}$ & $6 \cdot 4,7.9$ & $9 \cdot 7$ & $8 \cdot 7,10 \cdot 7$ & $<0.001$ \\
\hline Glycaemic index & Low & & Moderate & & High & & \\
\hline Protein (\%) & $15 \cdot 3^{*} \dagger$ & $14 \cdot 9,15 \cdot 6$ & $15 \cdot 8$ & $15 \cdot 5,16 \cdot 2$ & $15 \cdot 9$ & $15 \cdot 4,16 \cdot 4$ & 0.04 \\
\hline Alcohol (E\%) & $2 \cdot 6$ & $1.9,3.3$ & 2.6 & $2 \cdot 0,3 \cdot 3$ & $2 \cdot 0$ & $1 \cdot 2,2 \cdot 8$ & 0.43 \\
\hline
\end{tabular}

LF, low-fat; E\%, percentage of energy.

Mean value was significantly different from that for control: ${ }^{*} P<0.05$, ${ }^{\star \star \star} P<0.001$ (pairwise analyses).

Mean value was significantly different from that for LF: $\dagger P<0.05$, $\dagger+\dagger P<0.001$ (pairwise analyses)

$\ddagger$ Mean values for the three diets were compared with an ANOVA.

Blood samples were collected with minimal stasis using siliconised vacutainers and 21-gauge needles. First, $4.5 \mathrm{ml}$ blood were collected in $0.5 \mathrm{ml}$ of $0.129 \mathrm{M}$-trisodium citrate at room temperature for analyses of FVII, fibrinogen, D-dimer, TAG and total cholesterol, and $4.5 \mathrm{ml}$ blood were collected in $0.5 \mathrm{ml}$ of $0.129 \mathrm{M}$-trisodium citrate tubes on ice for analysis of prothrombin fragment $1+2(\mathrm{~F} 1+2)$. Finally, $4.5 \mathrm{ml}$ blood were collected in Stabilyte Tubes (Biopool, Umeå, Sweden) for analysis of PAI antigen.

Tubes collected at room temperature were centrifuged at $20^{\circ} \mathrm{C}$ for $20 \mathrm{~min}$ at $2000 \mathrm{~g}$. Tubes for analysis of $\mathrm{F} 1+2$ and PAI were centrifuged at $4^{\circ} \mathrm{C}$ for $20 \mathrm{~min}$ at $2000 \mathrm{~g}$. Plasma was pipetted into plastic vials and stored at $-70^{\circ} \mathrm{C}$.

\section{Blood analyses}

Plasma samples were rapidly thawed in a water-bath at $37^{\circ} \mathrm{C}$ and analysed in one series for each subject. Cholesterol and TAGs were determined enzymically with a COBAS INTEGRA (Roche, Mannheim, Germany). Plasma FVII:c was measured in a one-stage clotting assay using rabbit brain thromboplastin (Diagnostica Stago, Asnières, France). Fibrinogen concentrations were measured by a nephelometric method (Dade Behring, Marburg, Germany). A commercial ELISA (Enzygnost-F1 + 2; Dade Behring) was used to measure concentrations of $\mathrm{F} 1+2$. Rabbit anti-human $\mathrm{F} 1+2 \operatorname{IgG}$ was used as the first and second antibody. Concentrations of D-dimer were measured by an immunoturbidimetric method (STA-Liatest D-DI; Diagnostica Stago). PAI antigen was measured using an enzyme immunoassay (Haemochrom Diagnostica, Frederiksberg, Denmark).

\section{Statistics}

The statistical analyses were done on completers only and performed with the SPSS program (version 16.0; SPSS, Inc., Chicago, IL, USA). The distribution of the results for TAG, D-dimer, PAI and F1 +2 was skewed and values were logarithmically transformed before analysis. Fasting values were compared between the three diets at the start of intervention ( 0 months) and at the end of intervention (6 months) using an ANOVA. When significant betweendiet effects were observed, post hoc analyses were performed for pairwise analyses and adjusted for multiple comparisons by the Bonferroni test.

To test for differences within groups, fasting values at 6 months were compared with fasting values at 0 months for each of the three diets separately using a paired $t$ test. Furthermore, differences between diet groups in changes from month 0 to 6 for all variables were analysed by a univariate ANOVA using dietary group as a fixed factor and baseline values, changes in BMI, and changes in total cholesterol and TAG as covariates in order to adjust for possible confounders. In the case of significance in the ANOVA, pairwise analyses were performed.

Results are presented as mean values or geometric mean values and standard deviations. $P<0.05$ was considered statistically significant.

\section{Results}

We excluded seven study participants from the statistical calculations due to concentrations of C-reactive protein $(\mathrm{CRP})>10 \mathrm{mg} / \mathrm{l}(n \mathrm{6})$, indicating an inflammatory condition, or very high concentrations of intercellular adhesion molecule (ICAM) $(1434 \mathrm{ng} / \mathrm{ml} ; n 1)$, signifying pronounced endothelial cell dysfunction (results for CRP and ICAM will be published separately). These seven participants were distributed with three participants in the MUFA group, three participants in the LF group, and one participant in the control group.

There were no significant differences in baseline values (month 0) between the three experimental diets except for significant difference in BMI between the MUFA diet and the LF diet (Table 3). This difference persisted after 6 months $(P<0.01)$, with significant differences also between the MUFA diet and the control diet $(P<0.05)$. No other significant differences were observed after 6 months between the three diets (Table 3).

When the effects of 6 months of intervention were analysed within each dietary group, a significant increase in BMI and 
Table 3. Fasting concentrations of plasma variables before ( 0 months) and after (6 months) dietary intervention with a high-MUFA diet (MUFA; $n$ 36), a low-fat diet (LF; $n 40$ ) or a control diet ( $n$ 23)

(Mean values and standard deviations)

\begin{tabular}{|c|c|c|c|c|c|}
\hline \multirow[b]{2}{*}{ Variable } & \multicolumn{2}{|c|}{0 months } & \multicolumn{2}{|c|}{6 months } & \multirow[b]{2}{*}{$P \ddagger$} \\
\hline & Mean & SD & Mean & SD & \\
\hline \multicolumn{6}{|c|}{ BMI $\left(\mathrm{kg} / \mathrm{m}^{2}\right)$} \\
\hline MUFA & $28.42 \dagger$ & $2 \cdot 38$ & $29 \cdot 70^{*} \dagger$ & $2 \cdot 80$ & $<0.00$ \\
\hline LF & $26 \cdot 97$ & 2.09 & $27 \cdot 68$ & $2 \cdot 36$ & $<0.001$ \\
\hline Control & $27 \cdot 47$ & 1.80 & $28 \cdot 11$ & 1.79 & $<0.05$ \\
\hline \multicolumn{6}{|c|}{ TAG $(\mathrm{mmol} / \mathrm{l}) \S$} \\
\hline MUFA & 0.93 & 1.48 & 0.82 & 1.48 & 0.12 \\
\hline LF & 1.05 & 1.52 & 0.92 & 1.48 & $<0.05$ \\
\hline Control & 1.05 & 1.46 & 0.96 & 1.46 & 0.15 \\
\hline \multicolumn{6}{|c|}{ Cholesterol (mmol/l) } \\
\hline MUFA & 4.49 & 0.71 & 4.42 & 0.69 & 0.52 \\
\hline LF & 4.52 & 0.93 & 4.52 & 1.04 & 0.98 \\
\hline Control & $4 \cdot 40$ & 0.65 & $4 \cdot 64$ & 0.92 & 0.059 \\
\hline \multicolumn{6}{|l|}{ FVII:C (\%) } \\
\hline MUFA & 96 & 19 & 96 & 19 & 0.99 \\
\hline LF & 96 & 23 & 97 & 24 & 0.86 \\
\hline Control & 100 & 19 & 104 & 16 & $0 \cdot 17$ \\
\hline \multicolumn{6}{|c|}{ D-dimer $(\mu \mathrm{g} / \mathrm{ml}) \S$} \\
\hline MUFA & $0 \cdot 27$ & 1.61 & 0.21 & 1.51 & $<0.05$ \\
\hline LF & 0.29 & 1.61 & 0.24 & 1.54 & $<0.05$ \\
\hline Control & 0.30 & 1.66 & 0.27 & 1.78 & 0.056 \\
\hline \multicolumn{6}{|c|}{ PAI (ng/ml)§ } \\
\hline MUFA & 3.43 & 2.97 & 6.02 & 2.53 & $<0.001$ \\
\hline LF & 3.47 & 2.51 & $5 \cdot 01$ & $2 \cdot 35$ & $<0.01$ \\
\hline Control & 3.36 & $2 \cdot 95$ & $5 \cdot 82$ & $2 \cdot 94$ & $<0.001$ \\
\hline \multicolumn{6}{|c|}{$\mathrm{F} 1+2(\mathrm{pmol} / \mathrm{l}) \S$} \\
\hline MUFA & $158 \cdot 63$ & 1.40 & $157 \cdot 73$ & 1.56 & 0.93 \\
\hline LF & $157 \cdot 31$ & 1.32 & 153.06 & 1.45 & 0.45 \\
\hline Control & 169.05 & 1.64 & $160 \cdot 48$ & 1.33 & 0.63 \\
\hline
\end{tabular}

FVII:c, blood coagulation factor VII; PAI, plasminogen activator inhibitor; F1 + 2, prothrombin fragment $1+2$.

${ }^{*}$ Mean value was significantly different from that for control $(P<0.05)$.

$\dagger$ Mean value was significantly different from that for LF $(P<0.05)$.

$\ddagger$ Mean values at 0 months and 6 months were compared with a paired $t$ test within diet groups. Between-diet comparisons at 0 months and 6 months were performed with an ANOVA. When significant between-diet effects were observed, pairwise comparisons were performed with the Bonferroni test.

§D-dimer, PAI, F1 + 2 and TAG were logarithmically transformed before analysis (geometric mean and SD).

PAI and a significant decrease in D-dimer was observed on the MUFA diet. For the LF diet a significant increase in BMI and PAI and a significant decrease in TAG, fibrinogen and D-dimer were observed. For the control diet there was a significant increase in BMI and PAI and a significant decrease in fibrinogen and an almost significant decrease in D-dimer $(P=0.056)$ and cholesterol $(P=0.059) \quad($ Table 3$)$. No significant changes were observed in FVII:c and F1 + 2 (Table 3).

Significant differences between diet groups in changes from month 0 to 6 were only observed for changes in fibrinogen $(P<0 \cdot 05)$. Similar results were observed after adjustment for baseline values, changes in BMI and changes in lipids $(P<0 \cdot 05)$. This was due to significantly different fibrinogen changes during 6 months between the MUFA diet $\left(\Delta\right.$ fibrinogen $0 \rightarrow 6$ months $\left._{\text {MUFA }}=-0.11(\mathrm{SD} 0.44) \mathrm{g} / \mathrm{l}\right)$ and the LF diet $\left(\Delta\right.$ fibrinogen $0 \rightarrow 6$ months $_{\mathrm{LF}}=-0.38(\mathrm{SD}$ $0.48) \mathrm{g} / \mathrm{l})(P<0.05)$ and between the LF diet and the control diet $\left(\Delta\right.$ fibrinogen $0 \rightarrow 6$ months $_{\text {CONTROL }}=-0 \cdot 17(\operatorname{SD} 0 \cdot 39)$ $\mathrm{g} / \mathrm{l})(P<0 \cdot 01)$, with the most pronounced fibrinogen reduction on the LF diet (Fig. 2).
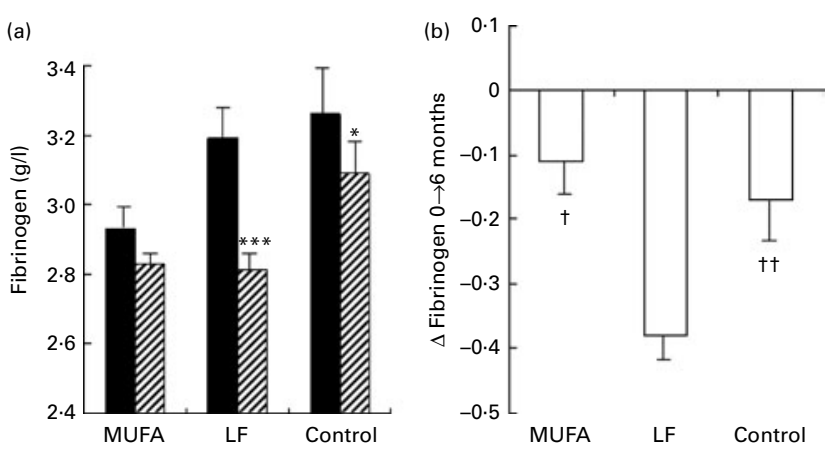

Fig. 2. Effects of the high-MUFA diet (MUFA), the low-fat diet (LF) and the control diet on (a) concentrations of fibrinogen ( $\mathrm{g} / \mathrm{l})$ before ( 0 months; $\mathbf{\square}$ ) and after 6 months $(\mathbb{Q})$ of dietary intervention and (b) changes in fibrinogen concentrations $(\mathrm{g} / \mathrm{l})$ during 6 months of dietary intervention ( $\Delta$ fibrinogen $0 \rightarrow 6$ months). Values are means, with standard errors represented by vertical bars. Mean value was significantly different from that at 0 months: ${ }^{\star} P<0.05$, ${ }^{* * *} P<0.001$. Mean value was significantly different from that for $L F$ : † $P<0.05$, †† $P<0.01$.

\section{Discussion}

In this weight-loss maintenance study, the fibrinogen concentration was significantly lowered by the LF diet, and not by the MUFA diet (Table 3). Changes in fibrinogen concentrations during 6 months differed significantly between diet groups, with the most pronounced fibrinogen reduction on the LF diet (Fig. 2). Furthermore, we observed significant increases in BMI and PAI concentration and significant reductions in D-dimer concentrations irrespective of the experimental diet.

The observed effects on fibrinogen suggest a less favourable cardiovascular effect of the MUFA diet compared with the LF diet. Also, fibrinogen concentrations increase after 3 weeks on a high-MUFA diet compared with a low-fat-high-fibre $\operatorname{diet}^{(19)}$, and linoleic acid (PUFA) raises fibrinogen compared with intake of $\mathrm{SFA}^{(20)}$. Other studies find no effect on fibrinogen, when comparing a MUFA diet with a SFA $\operatorname{diet}^{(21)}$, a PUFA diet ${ }^{(22)}$ or a low-fat $\operatorname{diet}^{(23)}$. Also, fat and fibre quantity do not seem to influence fibrinogen ${ }^{(24,25)}$. We cannot exclude that the significantly higher body weight in the MUFA group may partly explain the less favourable fibrinogen effect of the MUFA diet.

The dietary effect on fibrinogen can be reinforced by the observed reduction in D-dimer, which can release IL-6 from monocytes and consequently affect the hepatic synthesis of fibrinogen ${ }^{(26)}$. Only a single dietary study has measured D-dimer, with no differences in D-dimer between a highMUFA diet and a high-PUFA diet eaten for 4 weeks ${ }^{(22)}$. Most likely, lowering of D-dimer by all three dietary regimens in the present study indicates that the controlled study in itself had a healthy effect on the study participants, and that all three experimental diets were healthier than the habitual diets eaten by the overweight study participants. Alternatively, a decrease over time can be caused by a seasonal variation, but there seems to be only a minor variation in D-dimer, with maximum values in February and March ${ }^{(27)}$.

It seems unlikely that fibrinogen and D-dimer concentrations are lowered due to decreased coagulation activation, as no significant changes were observed in FVII and F1 +2 . It was previously observed that low-fat-high-fibre diets 
lower FVII:c compared with high-fat-low-fibre diets ${ }^{(24,25)}$, but the differences in amount of fat and fibre were larger than in the present study. A high-MUFA diet lowers FVII:c in some studies ${ }^{(19,22,28)}$, whereas other highly controlled studies cannot confirm the effect of fat quality on FVII: c $^{(21,29,30)}$. Only a few dietary studies have included measurements of $F 1+2$. Fat quality ${ }^{(30)}$ and fibre quantity ${ }^{(22)}$ do not seem to influence $\mathrm{F} 1+2$, but the type of saturated fat may be of importance ${ }^{(31)}$.

After an initial weight loss on the 8-week low-energy diet, the study participants regained $2-3 \mathrm{~kg}$ during the 6 -month intervention study irrespective of $\operatorname{diet}^{(15)}$. As expected, the weight regain was accompanied by an increase in PAI concentration in all groups irrespective of diet. In the ANOVA, however, changes in BMI during 6 months had no significant effect on changes in PAI, suggesting that the minor weight regain was not a major determinant of the increase in PAI. One explanation could be that the observed increase in PAI is caused by seasonal variation. Seasonal variation in PAI has been observed by Fröhlich et al. ${ }^{(32)}$, but with maximum concentration in March. Other studies cannot confirm such a variation in $\mathrm{PAI}^{(24,33,34)}$. Whatever the reason for the increase in PAI during the study period, the three experimental diets affected PAI to a similar extent. Other studies have demonstrated that MUFA-rich diets can reduce PAI activity or antigen compared with low-fat or -SFA diets ${ }^{(23,35)}$. Also, a low-GI diet can reduce PAI activity or antigen compared with high-GI or low-fat diets ${ }^{(12,36)}$. Other studies found no effects of fat quality and quantity on PAI concentrations ${ }^{(25,28,37)}$.

Thus, many short-term studies have indicated that MUFA-rich diets, low-fat-high-fibre diets, and diets with a low GI have beneficial effects on selected haemostatic variables. An exception is fibrinogen, which may be adversely affected by high-MUFA diets. However, various conflicting results have been reported. One major reason is that it is extremely difficult to standardise dietary studies and to completely control what individuals are eating. For the same reason, only very few long-term controlled dietary studies exist, and our randomised controlled long-term study adds important information to our present knowledge.

Important strengths of the present study include the randomised design, the long-term observation, the number of subjects, and the highly controlled supermarket model providing complex ad libitum diets for free-living individuals. The haemostatic variables were not among the primary effect variables in the power calculation (which was based on changes in body weight) ${ }^{(18)}$, but highly significant differences were observed for PAI, D-dimer and fibrinogen, and there was not even a trend towards differences in F1 +2 and FVII:c. We cannot exclude that we were unable to detect a true effect of the MUFA diet on fibrinogen due to a type 2 error, which may also be the reason for the lack of significance when comparing the three diets after 6 months (unpaired design), or due to the significantly higher body weight in the MUFA group. However, adjusting for baseline BMI in the ANOVA makes the difference between fibrinogen changes even more significant $(P<0 \cdot 01)$ (results not shown). A limitation of the study is the weight regain in all three dietary groups, which makes comparison with isoenergetic dietary studies more difficult. Also, 3 weeks of standardisation after the initial weight loss probably has a favourable effect on the haemostatic variables, thereby lowering the true effects of the experimental diets compared with the habitual diet in overweight individuals. Unfortunately, no blood samples were obtained at study start before weight loss, i.e. baseline samples were obtained after the standardisation period. Marckmann et al. have previously demonstrated a sustained improvement in FVII:c, fibrinogen and PAI after a major weight loss followed by a low-fat ad libitum maintenance $\operatorname{diet}^{(38)}$. However, the study aim was to compare the longterm effect of three dietary regimens on haemostatic variables during weight maintenance, and in relatively young subjects. An older (and more atherosclerotic or insulin-resistant) study population might have caused a greater difference in haemostatic variables within and between the diets.

In conclusion, the MUFA diet was not superior to the LF diet with respect to long-term effects on haemostatic variables in overweight subjects after weight loss. Only the LF diet lowered plasma fibrinogen, which is a well-documented cardiovascular risk marker, and changes in fibrinogen concentrations were affected significantly different between diets, with the most favourable fibrinogen reduction on the LF diet and no significant reduction on the MUFA diet. All three diets had similar long-term effects on D-dimer (favourable reductions) and PAI concentrations (disadvantageous increments). No effects on thrombin generation were observed. Thus, the thrombotic risk profile seems to be improved most favourably by the LF diet compared with the MUFA diet based on the reduction in fibrinogen concentration.

\section{Acknowledgements}

The authors wish to thank the project staff of the Department of Human Nutrition. The technicians Kathrine Overgaard and Anette Larsen are kindly thanked for analysing the blood samples. We would also like to give special thanks to Professor Walter Willett, Department of Epidemiology and Nutrition, Harvard School of Public Health, Boston, Massachusetts, USA and David Ludwig MD, PhD, Department of Medicine, Children's Hospital, Boston, Massachusetts, USA for participating in the design of the project.

The work was supported by the HA Foundation, The Danish Heart Association, The Danish Diabetes Association, Centre for Advanced Food Research, The state Research Councils, and The Danish Pork Council foundations, associations, and research councils: www.mufobes.dk/?show $=$ sponsorer. Foods in the supermarket and low-energy diets were sponsored by Nutrillett, the HA Foundation, KGT/DEG, The Danish Pork Council, Danisco FDB, Arla Foods, The Danish Heart Association, andLMCRådighedsfond. The food sponsors were: 3-Stjernet, Aarhus United, Allara, Ardo/ Frigodan, Beauvais, Bæchs Conditori, Bähncke, Cadiso, Cerealia, Daloon, Danisco, FDB, Flensted, Frisko, G-kartofler, Gamba Food, Jan Import, Kellogg's, Kims, Kraft Foods, Kryta, Københavns Engros Grønttorv, Kødbranchens Fællesråd, LCH Catering, Lykkeberg, Malaco Leaf, Nutana, Nutrillett, Odense Marcipan, Polar Is, Puratos, Rose Poultry, Rynkeby, Saeby, Santa Maria, Schulstad, Svansø, Sønderjysk Kål, Tholstrup Cheese, Toms, Tulip, Unilever, Urtekram 
and Wasa. Analyses of blood samples were supported by The Faculty of Health Sciences, The University of Southern Denmark.

The authors' contributions were: A. A., T. M. L. and A. D., study concept and design; A. D. and T. M. L., collection of data; E.-M. B., J. J. and S. S., blood analyses; E.-M. B., statistical analysis; E.-M. B. and J. J., interpretation of data; E.-M. B., drafting of the manuscript; E.-M. B., A. D., T. M. L., J. J., S. S. and A. A., critical revision of the manuscript for important intellectual content; A. A., T. M. L. and A. D., obtained funding; A. D., T. M. L., E.-M. B., J. J., S. S. and A. A., administrative, technical, or material support; A. A., study supervision. No sponsor participated in the analysis or interpretation of the data, manuscript preparation, review, or approval, or the decision to publish.

The authors declare no conflicts of interest.

\section{References}

1. Hu FB, Stampfer MJ, Manson JE, et al. (1997) Dietary fat intake and the risk of coronary heart disease in women. $N$ Engl J Med 337, 1491-1499.

2. Liu S, Willett WC, Stampfer MJ, et al. (2000) A prospective study of dietary glycemic load, carbohydrate intake, and risk of coronary heart disease in US women. Am J Clin Nutr 71, $1455-1461$.

3. Willett WC (2002) Eat, Drink, and be Healthy: The Harward Medical School Guide to Healthy Eating. New York, NY: Simon \& Schuster.

4. Danesh J, Lewington S, Thompson SG, et al. (2005) Plasma fibrinogen level and the risk of major cardiovascular diseases and nonvascular mortality: an individual participant meta-analysis. JAMA 294, 1799-1809.

5. Danesh J, Whincup P, Walker M, et al. (2001) Fibrin D-dimer and coronary heart disease: prospective study and meta-analysis. Circulation 103, 2323-2327.

6. Juhan-Vague I, Pyke SD, Alessi MC, et al. (1996) Fibrinolytic factors and the risk of myocardial infarction or sudden death in patients with angina pectoris. ECAT Study Group. European Concerted Action on Thrombosis and Disabilities. Circulation 94, 2057-2063.

7. Kohler HP \& Grant PJ (2000) Plasminogen-activator inhibitor type 1 and coronary artery disease. $N$ Engl J Med 342, 1792-1801.

8. De Stavola BL \& Meade TW (2007) Long-term effects of hemostatic variables on fatal coronary heart disease: 30-year results from the first prospective Northwick Park Heart Study (NPHS-I). J Thromb Haemost 5, 461-471.

9. Bladbjerg EM, Marckmann P, Sandstrom B, et al. (1994) Non-fasting factor VII coagulant activity (FVII:c) increased by high-fat diet. Thromb Haemost 71, 755-758.

10. Bladbjerg EM, Munster AM, Marckmann P, et al. (2000) Dietary factor VII activation does not increase plasma concentrations of prothrombin fragment $1+2$ in patients with stable angina pectoris and coronary atherosclerosis. Arterioscler Thromb Vasc Biol 20, 2494-2499.

11. Marckmann P, Bladbjerg EM \& Jespersen J (1998) Diet and blood coagulation factor VII - a key protein in arterial thrombosis. Eur J Clin Nutr 52, 75-84.

12. Ebbeling CB, Leidig MM, Sinclair KB, et al. (2005) Effects of an ad libitum low-glycemic load diet on cardiovascular disease risk factors in obese young adults. Am J Clin Nutr 81, 976-982.

13. Ebbeling CB, Leidig MM, Feldman HA, et al. (2007) Effects of a low-glycemic load vs low-fat diet in obese young adults: a randomized trial. JAMA 297, 2092-2102.
14. McMillan-Price J, Petocz P, Atkinson F, et al. (2006) Comparison of 4 diets of varying glycemic load on weight loss and cardiovascular risk reduction in overweight and obese young adults: a randomized controlled trial. Arch Intern Med 166, 1466-1475.

15. Due A, Larsen TM, Mu $\mathrm{H}$, et al. (2008) Comparison of 3 ad libitum diets for weight-loss maintenance, risk of cardiovascular disease, and diabetes: a 6-mo randomized, controlled trial. Am J Clin Nutr 88, 1232-1241.

16. Rasmussen LG, Larsen TM, Mortensen PK, et al. (2007) Effect on 24-h energy expenditure of a moderate-fat diet high in monounsaturated fatty acids compared with that of a low-fat, carbohydrate-rich diet: a 6-mo controlled dietary intervention trial. Am J Clin Nutr 85, 1014-1022.

17. Skov AR, Toubro S, Raben A, et al. (1997) A method to achieve control of dietary macronutrient composition in ad libitum diets consumed by free-living subjects. Eur J Clin Nutr 51, 667-672.

18. Due A, Larsen TM, Hermansen K, et al. (2008) Comparison of the effects on insulin resistance and glucose tolerance of 6-mo high-monounsaturated-fat, low-fat, and control diets. Am J Clin Nutr 87, 855-862.

19. Junker R, Pieke B, Schulte H, et al. (2001) Changes in hemostasis during treatment of hypertriglyceridemia with a diet rich in monounsaturated and $n-3$ polyunsaturated fatty acids in comparison with a low-fat diet. Thromb Res 101, 355-366.

20. Sanders TA, Oakley FR, Miller GJ, et al. (1997) Influence of $n-6$ versus $n-3$ polyunsaturated fatty acids in diets low in saturated fatty acids on plasma lipoproteins and hemostatic factors. Arterioscler Thromb Vasc Biol 17, 3449-3460.

21. Smith RD, Kelly CN, Fielding BA, et al. (2003) Long-term monounsaturated fatty acid diets reduce platelet aggregation in healthy young subjects. Br J Nutr 90, 597-606.

22. Turpeinen AM \& Mutanen M (1999) Similar effects of diets high in oleic or linoleic acids on coagulation and fibrinolytic factors in healthy humans. Nutr Metab Cardiovasc Dis 9, 65-72.

23. Lopez-Segura F, Velasco F, Lopez-Miranda J, et al. (1996) Monounsaturated fatty acid-enriched diet decreases plasma plasminogen activator inhibitor type 1. Arterioscler Thromb Vasc Biol 16, 82-88.

24. Marckmann P, Sandstrom B \& Jespersen J (1993) Favorable long-term effect of a low-fat/high-fiber diet on human blood coagulation and fibrinolysis. Arterioscler Thromb 13, 505-511.

25. Marckmann P, Sandstrom B \& Jespersen J (1994) Low-fat, high-fiber diet favorably affects several independent risk markers of ischemic heart disease: observations on blood lipids, coagulation, and fibrinolysis from a trial of middleaged Danes. Am J Clin Nutr 59, 935-939.

26. Robson SC, Shephard EG \& Kirsch RE (1994) Fibrin degradation product D-dimer induces the synthesis and release of biologically active IL-1 $\beta$, IL- 6 and plasminogen activator inhibitors from monocytes in vitro. Br J Haematol 86, 322-326.

27. Rudnicka AR, Rumley A, Lowe GD, et al. (2007) Diurnal, seasonal, and blood-processing patterns in levels of circulating fibrinogen, fibrin D-dimer, C-reactive protein, tissue plasminogen activator, and von Willebrand factor in a 45 year-old population. Circulation 115, 996-1003.

28. Allman-Farinelli MA, Gomes K, Favaloro EJ, et al. (2005) A diet rich in high-oleic-acid sunflower oil favorably alters low-density lipoprotein cholesterol, triglycerides, and factor VII coagulant activity. J Am Diet Assoc 105, 1071-1079.

29. Foley M, Ball M, Chisholm A, et al. (1992) Should mono- or poly-unsaturated fats replace saturated fat in the diet? Eur $J$ Clin Nutr 46, 429-436.

30. Larsen LF, Jespersen J \& Marckmann P (1999) Are olive oil diets antithrombotic? Diets enriched with olive, rapeseed, or sunflower oil affect postprandial factor VII differently. Am J Clin Nutr 70, 976-982. 
31. Bladbjerg EM, Tholstrup T, Marckmann P, et al. (1995) Dietary changes in fasting levels of factor VII coagulant activity (FVII:c) are accompanied by changes in factor VII protein and other vitamin K-dependent proteins. Thromb Haemost $\mathbf{7 3}$, 239-242.

32. Fröhlich M, Sund M, Russ S, et al. (1997) Seasonal variations of rheological and hemostatic parameters and acute-phase reactants in young, healthy subjects. Arterioscler Thromb Vasc Biol 17, 2692-2697.

33. Marckmann P, Sandstrom B \& Jespersen J (1992) The variability of and associations between measures of blood coagulation, fibrinolysis and blood lipids. Atherosclerosis 96, 235-244.

34. Mavri A, Guzic-Salobir B, Salobir-Pajnic B, et al. (2001) Seasonal variation of some metabolic and haemostatic risk factors in subjects with and without coronary artery disease. Blood Coagul Fibrinolysis 12, 359-365.
35. Perez-Jimenez F, Castro P, Lopez-Miranda J, et al. (1999) Circulating levels of endothelial function are modulated by dietary monounsaturated fat. Atherosclerosis 145, 351-358.

36. Jensen L, Sloth B, Krog-Mikkelsen I, et al. (2008) A lowglycemic-index diet reduces plasma plasminogen activator inhibitor-1 activity, but not tissue inhibitor of proteinases- 1 or plasminogen activator inhibitor-1 protein, in overweight women. Am J Clin Nutr 87, 97-105.

37. Niskanen L, Schwab US, Sarkkinen ES, et al. (1997) Effects of dietary fat modification on fibrinogen, factor VII, and plasminogen activator inhibitor-1 activity in subjects with impaired glucose tolerance. Metabolism 46, 666-672.

38. Marckmann P, Toubro S \& Astrup A (1998) Sustained improvement in blood lipids, coagulation, and fibrinolysis after major weight loss in obese subjects. Eur J Clin Nutr 52, 329-333. 